\title{
A Multi-Level Research on the Antecedents and Consequences of Group Task Satisfaction
}

\author{
Xiumei Wu, Biyan Wen, Ming Du \\ School of Management, Jinan University, Guangzhou, China \\ Email: 1173788234@qq.com
}

Received 15 April 2015; accepted 19 May 2015; published 22 May 2015

Copyright $(02015$ by authors and Scientific Research Publishing Inc.

This work is licensed under the Creative Commons Attribution International License (CC BY).

http://creativecommons.org/licenses/by/4.0/

(c) (i) Open Access

\begin{abstract}
In this study, in order to examine antecedents and consequences of group task satisfaction, We collected 204 questionnaires with 35 hotel groups from 4 hotels located in Guangzhou and Shenzhen and used HLM to test the relationship between group task satisfaction and other variables in group level and individual level. The research findings show that employee individual job satisfaction mediates the effect of group task satisfaction on employee turnover intention and job performance; group task satisfaction mediates the positive effect of group cohesion and group job characteristics on individual job performance; group cohesion moderates the effect of individual job satisfaction on turnover intention and job performance.
\end{abstract}

\section{Keywords}

Group Job Characteristics, Group Cohesion, Group Task Satisfaction, Job Satisfaction, Turnover Intention, Job Performance

\section{Introduction}

In recent years, due to low switching cost and low salary of hotel employees, hotel employee turnover rate is high. The high employee turnover rate will cause certain pressure toward the human resources department, training department, finance department and management of hotels. Therefore, many hotel managers spent a lot of human, financial and material resources in seeking the reasons for high employee turnover rate and the corresponding solutions. Meanwhile, a heated discussion was also raised in the academic circle [1]-[3]. Many scholars explored the reasons from job satisfaction in individual level [4]-[7], but in our depth interview, a number of staff responded that no sense of belonging in the work and intriguing against each other among col- 
leagues were one of the important reasons that leaded to their turnover intention. Based on what mentioned above, this article mainly discusses how to improve the hotel employee job satisfaction in the group level in order to improve the employee job performance and reduce employee turnover rate.

\section{Research Review and Hypotheses}

\subsection{Group Task Satisfaction}

At present, the academic research on employee job satisfaction was more and more mature. However, the academic research on employee job satisfaction in group level is very rare. At the beginning of this century, Mason and Griffin [8] first put forward the concept of "Group Task Satisfaction" (GTS). They pointed out that GTS was a group-level concept, i.e. group members' consistent attitude to work task and work environment instead of the aggregation or the average of employee individual job satisfaction. Mason and Griffin [8] argued that measuring GTS should ask group members to assess their perceptions of job satisfaction in group level, namely using transformation reference object consensus method to measure. Empirical study about antecedents of group task satisfaction was little. So, the present study mainly explores the influence of two group-level variables (i.e. group cohesion and group job characteristics) on group task satisfaction.

\subsection{Group Cohesion and Group Task Satisfaction}

Concept of cohesion was first put forward by Lewin [9] who argued that cohesion was the "glue" of keeping group members together and maintaining the relationship between them. According to the team-member exchange theory, each member in the group will produce different emotional reactions when contacting with other members in the group, and one may spread to other members and produce similar sentiment. In a high-quality team-member exchange relationship group, positive emotion diffuses among group members, harmonious group climate forms, emotional cohesion increases among members, and the group members are more likely to gain the satisfaction from group relationship. On this basis, the author puts forward the hypothesis:

H1: Group cohesion has a significant positive influence on group task satisfaction.

\subsection{Group Job Characteristics and Group Task Satisfaction}

Group job characteristics, as the name implies, are inherent attributes of a group work or task. At present, a typical job characteristics theory proposed by Hackman and Oldham [10] showed that dimensions of job characteristics (i.e., task importance, autonomy, diversity, completeness, feedback) would affect employees' outcomes through "the key psychological state". Therefore, group job satisfaction, as a key psychological state in a group level, might be influenced by group job characteristics. Mason and Griffin [8] had also pointed out that group task satisfaction and job characteristics were correlated. For example, a challenging and significance tasks are more attractive than a regular task without any feedback. Job involvement, tasks diversity, task significance and other job characteristics would affect group members' job satisfaction. On this basis, the author concludes that:

H2: Group job characteristics have a significant positive influence on group job satisfaction.

\subsection{Group Task Satisfaction and Job Satisfaction}

Mason and Griffin [8] argues that group job satisfaction has a direct impact on employee's job satisfaction. The consistent work attitude among group members would prompt them to obey conduct code in the group and keep consistent with work attitude in the group, thus in a high overall satisfaction group, the members are more likely to experience the satisfaction with work. On this basis, the author puts forward hypothesis:

H3: group job satisfaction has significant positive influence on job satisfaction.

From the above, the author argues that group job characteristics and group cohesion do not directly affect employee job satisfaction, but indirectly affect it through group task satisfaction. On this basis, the author puts forward hypotheses:

H4a: Group task satisfaction mediates the positive influence group job characteristics on job satisfaction;

H4b: Group task satisfaction mediates the positive influence group cohesion on job satisfaction.

\subsection{The Mediating Effect of Individual Job Satisfaction}

The more satisfied employees are more willing to stay in the enterprise instead of quitting [11], i.e. employee 
job satisfaction negatively correlates with turnover intention. In addition, employees with high job satisfaction are more likely to love the job, to be highly engaged in job and to improve job performance. Therefore satisfied employees would improve their job performance. Combining with hypothesis 3 , the author proposes hypotheses:

H5a: Employee job satisfaction mediates the negative influence of group task satisfaction on turnover intention;

H5b: Employee job satisfaction mediates the positive influence of group task satisfaction on job performance.

\subsection{The Moderating Effect of Group Cohesion}

Little research regarded group cohesion as a moderator variable, and cross-level moderating effect was less. Group cohesion could be divided into two dimensions. One is emotional cohesion, also called social cohesion, which refers to close relationship among group members, and interdependence tendency formed in daily life in which they get along with each other. Another is task cohesion which puts emphasis on coordination and distribution of responsibilities and complementary skills of group members when they are completing group task together [12]. In a group of strong emotional cohesion, satisfied employees would emotionally attach to their group, reducing their turnover intention; in a group of strong task cohesion, group members would closely cooperate, improving job performance of their group. Therefore, the author concludes that:

H6a: Group cohesion moderates the positive effect of employee job satisfaction on turnover intention;

H6b: Group cohesion moderates the negative effect of employee job satisfaction on job performance.

From what has been discussed above, the author puts forward hypothesis model shown in Figure 1.

\section{Methodology}

\subsection{Sample}

The author issued formal questionnaires to the employees in the front-line service group and back office group of three five-star hotels and a four-star hotel in Guangzhou and Shenzhen. Before issuing, the author packed corresponding questionnaires into the envelope according to the number of each group and marked the group name on it to avoid packing by mistake. After employees completed, the author sealed the envelope and took them back. A total of 252 questionnaires from 40 groups were collected. Eliminating invalid questionnaires such as incomplete questionnaires, 204 questionnaires from 35 groups were valid, with an $81 \%$ effective rate. In the valid study samples, women accounted for 56.1\%; employee between 18 and 28 years old accounting for 74.6\%;between 29 and 45 years old accounting for 23.9\%; 46 years old or above accounting for 1.5\%; below high school degree, $43.4 \%$, college degree or above, 56.6\%; monthly income below 3000 RMB, $68.2 \%$, between 3000 and $8000,30.3 \%$, above $8000,1.5 \%$; respondents who work in current hotel are less than 1 year, 55.6\%, between 1 year and 5 years, 39.5\%, above 5 years, $4.9 \%$.

\subsection{Measures}

The measurements of key variables in present study adopt Likert 5-points scale, 1 for complete disagreement

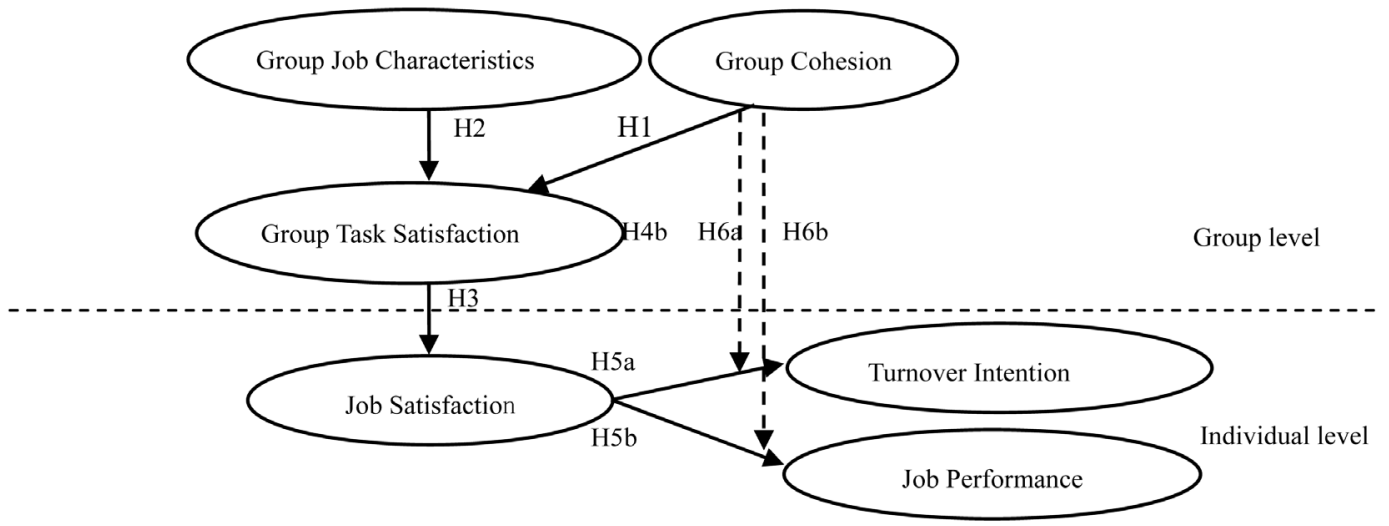

Figure 1. Research model. 
and 5 for complete agreement. Group task satisfaction (GTS) was measured with group task satisfaction scale developed by Mason and Griffin [13]. The measurement of group cohesion (GC) referred to group identity scale by Henry et al. [14], Henry et al. argued "group cohesion from the group identity". Group job characteristics (GJC) was measured with job diversity, autonomy and feedback three dimension, and items design referred to the study of Teas [15]. Job satisfaction (JS) was measured with job satisfaction 5-scale developed by Smith et al. [16]. The measurement of turnover intention (TI) referred to the scale developed by Wayne et al. [17]. The measurement of job performance (JP) referred to "task-contextual performance", two-dimension model proposed by Borman and Motowidlo [18].

\section{Results}

\subsection{Reliability and Validity Test}

Firstly, this research has adopted the SPSS17.0 to conduct exploratory factor analysis (EFA) of the three multidimensional variables, which are group task satisfaction, group job characteristic and group cohesion. The subscales of group task satisfaction and group job characteristics hold very high loads among their common factors; meanwhile, they have achieved convergent validity and discrimination validity. Among the sub-scales of group cohesion, the item coefficient of GC11 was less than 0.45, it had to be deleted; while GC3, GC5 and GC7 fell over the dimension of planned construct and they couldn't be explained easily, therefore, they also had to be deleted.

After revising the scale, this research will adopt LISREL8.80 to conducted the confirmatory factor analysis (CFA ) of group task satisfaction, group cohesion and group job characteristics, which furthermore will use indexes of $\times 2$ testing, RMSEA, NNFI, CFI, SRMR to judge the fitting degree of models. As shown in Table 1, the measurement models of group task satisfaction, group cohesion and group job characteristics basically fit the data, demonstrating that the scales have good construct validity. After reversion, all variables "Cronbach" $\alpha$ reached between 0.609 and 0.832 , which showed that the reliability of the scales reached acceptable scope.

\subsection{The Multilevel Linear Model Analysis}

Among the hierarchical linear models, level 1 (individual level) includes the employee's job satisfaction, turnover intention, job performance and control variables. Level 2 (group level) includes group job characteristics, group cohesion and group task satisfaction. RWG value, coefficient of ICC (1) and ICC (2) of employees' score of group job characteristics, group cohesion and group task satisfaction basically reached acceptable aggregation conditions recommended by Klein et al. [19]. Therefore, we aggregated the individual scores of the three variables to level 2 variable values.

\subsubsection{Analysis of Multilevel Main Effect and Moderating Effect}

Using HLM 6.08 software, the author carried out data analysis according to Hofman's multilevel linear model analysis method [20], and the analytic results demonstrates that (see Table 2):

1) After controlling the control variables, the independent variables of level 1 and independent variables of level 2 (i.e., group cohesion and group job characteristic), group task satisfaction had significant positive influence on employee job satisfaction $(\gamma 03=0.932$, $\mathrm{p}<0.01$ ), supporting H3; meanwhile group task satisfaction had no significant effect on employee turnover intention $(\gamma 03=-0.283, \mathrm{p}>0.1)$ and job performance $(\gamma 03=$ $-0.411, \mathrm{p}>0.1$ ).

2) After controlling the control variables and the independent variables of level 1 and independent variables of level 2, group cohesion had significant moderating effect on the relationship between employee job satisfac-

Table 1. Confirmatory factor analysis result.

\begin{tabular}{ccccccccc}
\hline Variable & df & $\chi 2$ & Significance & RESEA & SRMR & NNFI & 0.950 & 0.057 \\
Group task satisfaction & 32 & 51.150 & 0.00 & 0.061 & 0.087 & 0.054 & 0.910 \\
Group cohesion & 16 & 37.860 & 0.00 & 0.950 & 0.061 & 0.930 \\
Group job characteristic & 24 & 51.910 & 0.00 & 0.960 \\
\hline
\end{tabular}

$$
{ }^{*} \mathrm{p}<0.001 \text {. }
$$


Table 2. Analysis results of multilevel main effect and moderating effect.

\begin{tabular}{|c|c|c|c|c|}
\hline Models & Dependent variable & JS & TI & JP \\
\hline \multicolumn{5}{|c|}{ M1: Null model } \\
\hline Intercept & $\gamma_{00}$ & $3.35^{* *}$ & $2.46^{* *}$ & $5.47^{* *}$ \\
\hline $\mathrm{D}(\mathrm{NP})$ & & $432.65(2)$ & $479.11(2)$ & $496.48(2)$ \\
\hline \multicolumn{5}{|c|}{$\begin{array}{l}\text { M2: Random coefficient regression model } \\
\text { (Increase control variables of the level 1) }\end{array}$} \\
\hline Q01 & $\gamma_{10}$ & -0.02 & -0.06 & -0.09 \\
\hline Q02 & $\gamma_{20}$ & 0.11 & 0.02 & 0.10 \\
\hline Q03 & $\gamma_{30}$ & -0.02 & -0.01 & -0.09 \\
\hline Q04 & $\gamma_{40}$ & $-0.14^{* *}$ & -0.06 & 0.08 \\
\hline Q05 & $\gamma_{50}$ & $0.19^{* *}$ & 0.04 & 0.02 \\
\hline Q06 & $\gamma_{60}$ & -0.05 & -0.09 & $0.20^{+}$ \\
\hline $\mathrm{D}(\mathrm{NP})$ & & $417.33(9)$ & $474.42(9)$ & 466.90 (9) \\
\hline$\Delta \chi^{2}(\Delta \mathrm{df})$ & & $15.32(7)^{*}$ & $4.69(7)$ & $29.56(7)^{* *}$ \\
\hline \multicolumn{5}{|c|}{$\begin{array}{l}\text { M3: Random coefficient regression model } \\
\text { (Increase independent variable of the level 1) }\end{array}$} \\
\hline JS & $\gamma_{70}$ & & $-0.67^{* *}$ & $0.34^{* *}$ \\
\hline $\mathrm{D}(\mathrm{NP})$ & & & $389.45(12)$ & $425.32(12)$ \\
\hline$\Delta \chi^{2}(\Delta \mathrm{df})$ & & & $84.97(5)^{* *}$ & $41.58(5)^{* *}$ \\
\hline \multicolumn{5}{|c|}{$\begin{array}{l}\text { M4: Model of Intercept as results } \\
\text { (Increase control variables of the level 2) }\end{array}$} \\
\hline GC & $\gamma_{01}$ & 0.00 & 0.24 & $1.15^{* *}$ \\
\hline GJC & $\gamma_{02}$ & 0.00 & -0.15 & $0.61^{*}$ \\
\hline GTS & $\gamma_{03}$ & $0.93^{* *}$ & -0.28 & -0.41 \\
\hline $\mathrm{D}(\mathrm{NP})$ & & $397.80(12)$ & $387.06(15)$ & $416.45(15)$ \\
\hline$\Delta \chi^{2}(\Delta \mathrm{df})$ & & $19.53(5)^{* *}$ & 2.39 (3) & $8.87(3)^{*}$ \\
\hline \multicolumn{5}{|c|}{$\begin{array}{l}\text { M5: Model of slope as results } \\
\text { (Increase the hierarchical interactive items) }\end{array}$} \\
\hline $\mathrm{GC} \times \mathrm{JS}$ & $\gamma_{71}$ & & $-0.47^{*}$ & $0.54^{*}$ \\
\hline $\mathrm{D}(\mathrm{NP})$ & & & $383.38(16)$ & $412.60(16)$ \\
\hline$\Delta \chi^{2}(\Delta \mathrm{df})$ & & & $3.68(1)^{+}$ & $3.85(1)^{*}$ \\
\hline
\end{tabular}

Q01 = gender; Q02 = age; Q03 = education background; Q04 = length of service to the department; Q05 = position; Q06 = monthly income level. D represents deviation square; NP represents number of parameter estimated; $\Delta \times 2$ represents the difference between bias squares; $\Delta \mathrm{df}$ represents the difference between the degrees of freedom; ${ }^{* *} \mathrm{p}<0.01,{ }^{*} \mathrm{p}<0.05,{ }^{+} \mathrm{p}<0.1$.

tion and employee turnover intention $(\gamma 71=0.472, \mathrm{p}<0.05)$, and the relationship between job satisfaction and employee job performance $(\gamma 71=0.538, \mathrm{p}<0.05)$. The result of Chi-square test showed that M5 fitted data more than M4 $\left(\Delta \mathrm{x}^{2}=3.68, \Delta \mathrm{df}=1, \mathrm{p}<0.1\right.$; TI as DV) $\left(\Delta \mathrm{x}^{2}=3.85, \Delta \mathrm{df}=1, \mathrm{p}<0.05\right.$; JP as DV). According to Simple Slope (SS) test method by Cohen et al. [21], the author used HLM software to draw regression line (see Figures 2(a)-(b)) about stronger cohesion group (total average + standard deviation of group cohesion ) and weaker cohesion group (total average-standard deviation of group cohesion). The results showed that employee job satisfaction and turnover intention had a stronger negative correlation relationship in stronger cohesion group $(\mathrm{SS}=0.806, \mathrm{~T}(32)=9.314, \mathrm{p}<0.01)$ than in weaker cohesion group $(\mathrm{SS}=0.513, \mathrm{~T}(32)=4.476, \mathrm{p}<$ 0.01 ), therefore, H6a is supported. Employee job satisfaction and job performance has a stronger positive correlation relationship in stronger cohesion group (SS $=0.594, \mathrm{~T}(32)=5.700, \mathrm{p}<0.01$ ) than in weaker cohesion group ( $\mathrm{SS}=0.261, \mathrm{~T}(32)=2.201, \mathrm{p}<0.05$ ), therefore, H6b is supported. 


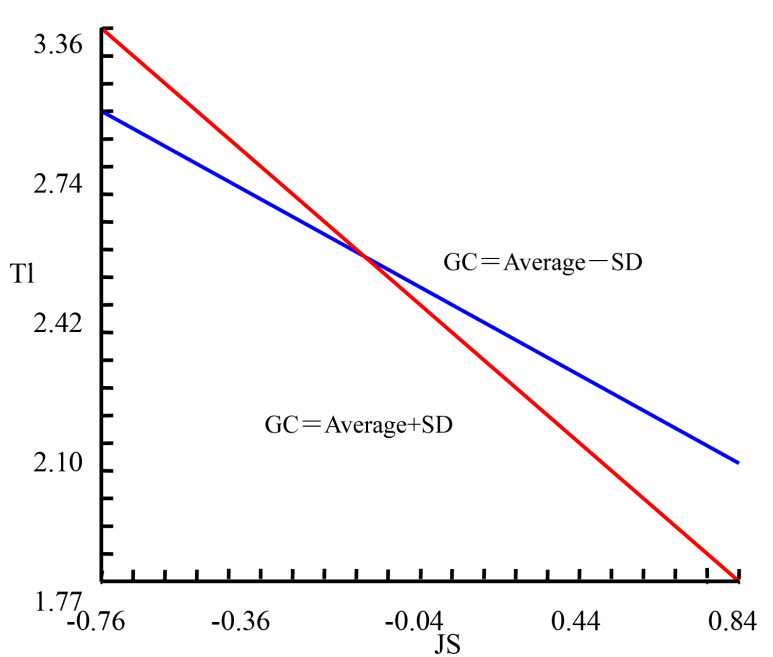

(a)

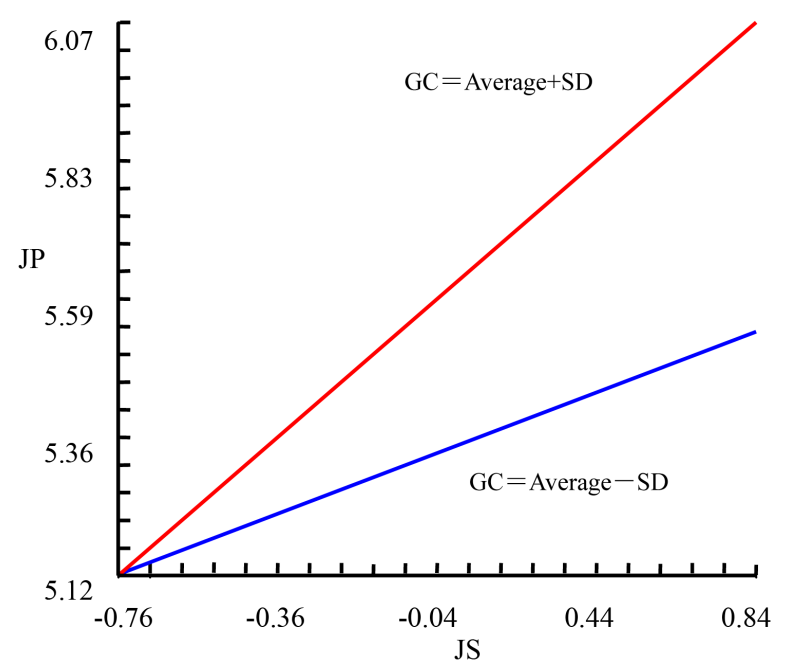

(b)

Figure 2. (a) Interaction effect of GC and JS on TI; (b) Interaction effect of GC and JS on JP.

\subsubsection{The Multilevel Mediating Effect Analysis}

In this study, with the mediation effect analysis method of Barron and Kenny [22], the author tested the mediation effect. The analysis results of multilevel mediation effect (see Table 3 ) indicate that 1 ) group characteristics $(\beta=0.330, \mathrm{p}<0.05)$ and group cohesion $(\beta=0.394, \mathrm{p}<0.01)$ has significantly positive influence on group task satisfaction, supporting $\mathrm{H} 1$ and $\mathrm{H} 2 ; 2)$ group task satisfaction fully mediates positive impact of group job characteristics $(\beta=0.929, \mathrm{p}<0.01)$ and group cohesion $(\beta=0.932, \mathrm{p}<0.01)$ on employee job satisfaction, supporting $\mathrm{H} 4 \mathrm{a}$ and $\mathrm{H} 4 \mathrm{~b}$; 3 ) employee job satisfaction fully mediates positive influence of group task satisfaction on employee turnover intention $(\beta=-0.654, \mathrm{p}<0.01)$ and job performance $(\beta=0.445, \mathrm{p}<0.01)$, supporting $\mathrm{H} 5 \mathrm{a}$ and H5b.

\section{Discussion and Conclusions}

This research has improved and deepened Mason and Griffin's group task satisfaction theory [8]. And we have verified that: 1) Group cohesion and group job characteristics have a significant positive impact on group task satisfaction, which are similar to empirical research findings of Seers [23], Dobbins et al. [24] and Kidwell et al. [25]; 2) Employees' perception of group task satisfaction has a significant positive impact on the job satisfaction in individual level, which is consistent with Mason and Griffin's finding; 3) Group job characteristics and group cohesion do not directly affect employees' individual job satisfaction, but indirectly affect it through group task satisfaction; group task satisfaction does not directly affect turnover intention and job performance, but indirectly affects them through individual job satisfaction, which further improves and extends Mason and Griffin's group task satisfaction theory; 4) Group cohesion across-level moderates the effect of individual job satisfaction on turnover intention and job performance. There is little research about the moderating effect of group cohesion, not mention the research about cross-level moderating effect, therefore, this finding provides a new perspective on the effect of group cohesion.

These research conclusions provide some revelations for hotel managers on how to reduce employee turnover intention and improve job performance from a group point of view. It is necessary for the hotel managers to create a high cohesive group to reduce the employee turnover rate and improve the employee job performance. In addition, hotel managers should also pay attention to the improvement of work diversity, autonomy and feedback. Especially in terms of autonomy, due to the limited mandate, the hotel junior employees only report to their superiors based on the principles of basic services when facing unexpected situations, which may result in service delays and other issues. At last, it may affect the customer experience and employee motivation initiative. Based on this, we think the group managers should give a reasonable authorization based on the group member personality, experience, skills, etc., in order to save time, avoid unnecessary delays in service and complaints, mobilize the member's initiation, and increase their sense of accomplishment. 
Table 3. Analysis results of multilevel mediation effect.

\begin{tabular}{|c|c|c|c|c|c|}
\hline \multicolumn{2}{|c|}{ Mediation model } & $\begin{array}{l}\text { Mediating effect of } \\
\text { GTS on GC and JS }\end{array}$ & $\begin{array}{l}\text { Mediating effect of } \\
\text { GTS on GJC and JS }\end{array}$ & $\begin{array}{l}\text { Mediating effect of } \\
\text { JS on GTS and TI }\end{array}$ & $\begin{array}{l}\text { Mediating effect of } \\
\text { JS on GTS and JP }\end{array}$ \\
\hline \multicolumn{2}{|c|}{ Step1: The influence of IV on DV } & $0.415^{+}$ & $0.373^{+}$ & $-0.830^{* *}$ & $0.720^{*}$ \\
\hline \multicolumn{2}{|c|}{ Step2: The influence of IV on MV } & ${ }^{\mathrm{a}} 0.330(0.143)^{*}$ & $0.394(0.118)^{* *}$ & $0.928(0.170)^{* *}$ & $0.928(0.170)^{* *}$ \\
\hline \multicolumn{2}{|c|}{ Step3: The influence of MV on DV } & $0.928(0.170)^{* *}$ & $0.928(0.170)^{* *}$ & $-0.674(0.071)^{* *}$ & $0.459(0.078)^{* *}$ \\
\hline \multirow{2}{*}{$\begin{array}{l}\text { Step4: The influence } \\
\text { IV and MV on DV }\end{array}$} & IV to DV & -0.008 & -0.002 & -0.255 & 0.380 \\
\hline & MV to DV & $0.932(0.182)^{* *}$ & $0.929(0.197)^{* *}$ & $-0.654(0.073)^{* *}$ & $0.445(0.080)^{* *}$ \\
\hline \multicolumn{2}{|c|}{$Z$ value } & $2.104(\mathrm{p}<0.05)$ & $2.725(\mathrm{p}<0.01)$ & $-4.662(\mathrm{p}<0.01)$ & $3.896(\mathrm{p}<0.01)$ \\
\hline
\end{tabular}

IV represents Independent variable; DV represents dependent variable; MV represents mediation variable. ${ }^{a}$ the first value is the regression coefficient, and the value in parentheses is the standard error; ${ }^{*} \mathrm{p}<0.05 ;{ }^{* *} \mathrm{p}<0.01$.

There are still some limitations in this research. First of all, we only investigated the hotel industry, so the general applicability of the findings needs testing. In addition, in this research, we failed to make paired questionnaires to collect data for the reason of operational difficulties, so there may be homologous error problems.

\section{Acknowledgements}

This research is funded by NSFC (71472075).

\section{References}

[1] Hwang, J., Lee J., Park, S., Chang, H. and Kim, S. (2014) The Impact of Occupational Stress on Employee’s Turnover Intention in the Luxury Hotel Segment. International Journal of Hospitality \& Tourism Administration, 15, 60-77. http://dx.doi.org/10.1080/15256480.2014.872898

[2] Ribeiro, N. and Semedo, A. (2014) Human Resources Management Practices and Turnover Intentions: The Mediating Role of Organizational Justice. IUP Journal of Organizational Behavior, 13, 7-32.

[3] Elanain, H. (2014) Leader-Member Exchange and Intent to Turnover Testing a Mediated-Effects Model in a High Turnover Work Environment. Management Research Review, 37, 110-129. http://dx.doi.org/10.1108/MRR-09-2012-0197

[4] Brunetto, Y., Teo, S.T., Shacklock, K. and Farr-Wharton, R. (2012) Emotional Intelligence, Job Satisfaction, WellBeing and Engagement: Explaining Organizational Commitment and Turnover Intentions in Policing. Human Resource Management Journal, 22, 428-441. http://dx.doi.org/10.1111/j.1748-8583.2012.00198.x

[5] Wang, Y.-D., Yang, C. and Wang, K.-Y. (2012) Comparing Public and Private Employees’ Job Satisfaction and Turnover. Public Personnel Management, 41, 557-573. http://dx.doi.org/10.1177/009102601204100310

[6] Kanwar, Y.S., Singh, A.K. and Kodwani, A. (2012) A Study of Job Satisfaction, Organizational Commitment and Turnover Intent among the IT and ITES Sector Employees. The Journal of Business Perspective, 16, 27-35. http://dx.doi.org/10.1177/097226291201600103

[7] Chen, G., Ployhart, R.E., Thomas, H., Anderson, N. and Bliese, P.D. (2011) The Power of Momentum: A New Model of Dynamic Relationships between Job Satisfaction Change and Turnover Intentions. Academy of Management Journal, 54, 159-181. http://dx.doi.org/10.5465/AMJ.2011.59215089

[8] Mason, C.M. and Griffin, M.A. (2002) Group Task Satisfaction: Applying the Construct of Job Satisfaction to Groups. Small Group Research, 33, 271-312. http://dx.doi.org/10.1177/10496402033003001

[9] Lewin, K. (1952) Field Theory in Social Science. Harper \&Row, New York.

[10] Hackman, J.R. and Oldham, G.R. (1975) Development of the Job Diagnostic Survey. Journal of Applied Psychology, 60, 159-170. http://dx.doi.org/10.1037/h0076546

[11] Porter, L.W. and Steers, R.M. (1973) Organizational, Work, and Personal Factors in Employee Turnover and Absenteeism. Psychological Bulletin, 80, 151-176. http://dx.doi.org/10.1037/h0034829

[12] Zaccaro, S.J. and Mccoy, M.C. (1988) The Effects of Task and Interpersonal Cohesiveness on Performance of a Disjunctive Group Task. Journal of Applied Social Psychology, 18, 837-851. http://dx.doi.org/10.1111/j.1559-1816.1988.tb01178.x

[13] Mason, C.M. and Griffin, M.A. (2005) Group Task Satisfaction: The Group’s Shared Attitude to Its Task and Work 
Environment. Group and Organization Management, 30, 625-652. http://dx.doi.org/10.1177/1059601104269522

[14] Henry, K.B., Arrow, H. and Carini, B. (1999) A Tripartite Model of Group Identification: Theory and Measurement. Small Group Research, 30, 558-581. http://dx.doi.org/10.1177/104649649903000504

[15] Teas, R.K. (1981) Selling Task Characteristics and the Job Satisfaction of Industrial Salespeople. Journal of Personal Selling \& Sales Management, 1, 18-25.

[16] Smith, P.C., Kendall, L.M. and Hulin, C.L. (1969) The Measurement of Satisfaction in Work and Retirement. Rand McNally and Company, Chicago.

[17] Wayne, S.J., Shore, L.M. and Liden, R.C. (1997) Perceived Organizational Support and Leader Member Exchange: A Social Exchange Perspective. Academy of Management Journal, 40, 82-111. http://dx.doi.org/10.2307/257021

[18] Borman, W.C. and Motowidlo, S.J. (1993) Expanding the Criterion Domain to Include Elements of Contextual Performance. In: Schmitt, N. and Borman, W.C., Eds., Personnel Selection in Organization, Jossey Bass, San Francisco, 7178.

[19] Klein, K.J., Bliese, P.D., Kozlowski, S.W.J., Dansereau, F., Gavin, M.B., Griffin, M.A., et al., (2000) Multilevel Analytical Techniques: Commonalities, Differences and Continuing Questions. In: Klein, K.J. and Kozlowski, S.W.J., Eds., Multilevel Theory, Research, and Methods in Organizations: Foundations, Extensions, and New Directions, JosseyBass, San Francisco, 512-553.

[20] Hofmann, D.A. (1997) An Overview of the Logic and Rationale of Hierarchical Linear Models. Journal of Management, 23, 723-744. http://dx.doi.org/10.1177/014920639702300602

[21] Cohen, J., Cohen, P., West, S.G. and Aiken, L.S. (2003) Applied Multiple Regression/Correlation Analysis for the Behavioral Sciences. 3rd Edition, Lawrence Erlbaum Associates, Mahwah, 267-300.

[22] Baron, R.M. and Kenny, D.A. (1986) The Moderator-Mediator Variable Distinction in Social Psychological Research: Conceptual, Strategic, and Statistical Considerations. Journal of Personality and Social Psychology, 51, 1173-1182. http://dx.doi.org/10.1037/0022-3514.51.6.1173

[23] Seers, A. (1989) Team-Member Exchange Quality: A New Construct for Role-Making Research. http://www.sciencedirect.com/science/article/pii/0749597889900605 - item1\#item1Organizational Behavior and Human Decision Processes, 43,118-135. http://dx.doi.org/10.1016/0749-5978(89)90060-5

[24] Dobbins, G.H. and Zaccaro, S.J. (1986) The Effects of Group Cohesion and Leader Behavior on Subordinate Satisfaction. Group \& Organization Management, 11, 203-219. http://dx.doi.org/10.1177/105960118601100305

[25] Kidwell, R.E., Mossholder, K.W. and Bennett, N. (1997) Cohesiveness and Organizational Citizenship Behavior: A Multilevel Analysis Using Work Groups and Individuals. Journal of Management, 23, 775-793.

http://dx.doi.org/10.1177/014920639702300605 